Research Article

\title{
Impact of teaching session on concepts of palliative care in medical undergraduates
}

\author{
Sirisha Annavarapu ${ }^{1}$, , Janardhan Marupaka ${ }^{1}$, Naveen kumar T.
}

\author{
${ }^{1}$ Department of Pharmacology, \\ Kamineni Institute of Medical \\ Sciencess, Narketpally, Nalgonda \\ Dist., Telangana, India, \\ ${ }^{2}$ Department of pharmacology, \\ Apollo Institute of Medical \\ Sciences and Research, \\ Hyderabad, Telangana, India
}

Received: 7 December 2015 Accepted: 7 January 2016

\section{*Correspondence to:}

Dr. Sirisha Annavarapu, Email: sirisha.annavarapu.1988 @ gmail.com

Copyright: (c) the author(s), publisher and licensee Medip Academy. This is an open-access article distributed under the terms of the Creative Commons Attribution Non-Commercial License, which permits unrestricted non-commercial use, distribution, and reproduction in any medium, provided the original work is properly cited.

\begin{abstract}
Background: The objective of this study is to evaluate the impact of teaching session on concepts of palliative care and pain management among medical undergraduate students in a tertiary care hospital.

Methods: The study was conducted in tertiary care teaching hospital among undergraduates. 152 medical students were enrolled. Pre-session questionnaire was distributed to the students and the response was obtained. This was followed by an educational lecture with power point presentation for 45 minutes and post-lecture response to the questionnaire was perceived. With comments, a qualitative mathematic analysis was carried out.
\end{abstract}

Results: With response of $90 \%$ the attitude of students regarding incurable terminal illness did not change due to educational training. Comparison of knowledge and attitude in precession and post session in $4^{\text {th }}$ year undergraduates was higher ( $\mathrm{p}$ value $<0.001 \&<0.0001$ ) in comparison to $2^{\text {nd }}$ year undergraduates ( $\mathrm{P}$ value $<0.0002 \&<0.0005)$. Post session mean assessment also showed slight increase for $4^{\text {th }}$ year $(45.6 \& 87.4)$ when compared with 2 nd year students (42.8 \& 82.12).

Conclusions: Concept of palliative care was poor among medical undergraduates. Health care providers can overcome by knowledge construction, interrelation between practice and evidence based medicine.

Keywords: Palliative care education, Professional knowledge, Questionnaire study

\section{INTRODUCTION}

Palliative care as defined by WHO is "an approach that improves the quality of life of patients and their families facing the problems associated with life-limiting illness, through the prevention and relief of suffering by means of early identification, impeccable assessment and treatment of pain and other problems physical, psychosocial, and spiritual". ${ }^{1}$ The primary areas of concern in palliative care include unresolved symptoms and complex psychosocial issues for patients with advanced disease, complex end of life issues, complex bereavement issues.

It is best administered by a multi-dimensional, interdisciplinary team comprising of doctors, nurses, physiotherapists, counsellors, pharmacists, social workers, volunteers, and family members. ${ }^{2}$
Studies show that doctors and health care professionals lack the ability to provide end-of-life care and cater to the needs of the dying patients due to the inadequate knowledge in administering the adequate dosages of analgesics and sedatives. ${ }^{3}$ Health professionals function largely within a culture that focuses on cure, and many avoid the patient who is dying. It is therefore vital that all health care practitioners have contact with people who are dying, including medical, allied health science, nursing and apply the best principles of palliative care.

Understanding the existing level of palliative care knowledge and attitudes toward end of life care would be an important benchmark for analysis of future educational effort. ${ }^{4}$ The objective of present study was to evaluate the knowledge about the concepts of palliative care among the medical undergraduate students using educational session. 


\section{METHODS}

The study was conducted in Kamineni Institute of Medical Sciences, Narketpally between June and August 2014. Target population for the study included undergraduate medical students (second and fourth year) and a total of 152 students participated in the study. Permission from institutional review board and written informed consent were obtained from subjects. The course compromised 50 hours. of teaching over a period of three months and topics were imparted by professor from palliative care. The topics covered are principles of palliative medicine, pain treatment, psychiatric, gastro intestinal, genitourinary, respiratory and neurological problems; ethical aspects of caring for terminally ill patients.

A 25-point questionnaire was prepared according to following criteria: multiple choice exam and a clinical case. The students who were unwilling to fill the questionnaire were excluded from the study. A pre-test informed consent was taken from every student participated in this study. Pre-session questionnaire was distributed to the students and the response was obtained. This was followed by an educational lecture with power point presentation for 45 minutes. Later, post-lecture response to the questionnaire was taken. Time of 30 minutes was given to each student for filling the questionnaire. Data was entered in Microsoft excel and percentages were used to summarize the data. The results were analyzed and compared.

\section{RESULTS}

Among the 152 medical students, who participated in the questionnaire study $49 \%$ belong to $2^{\text {nd }}$ year and $51 \%$ belong to 4 th year medical undergraduates. Males and female students included in the study are $36 \%$ and $64 \%$.

Table 1: Attitude of students regarding incurable terminal illness.

\begin{tabular}{|llll|}
\hline & $\begin{array}{l}\text { Natural } \\
\text { death }\end{array}$ & Euthanasia & Unsure \\
\hline Pre session & $60.5 \%$ & $29.6 \%$ & $9.9 \%$ \\
\hline Post session & $65.1 \%$ & $30.1 \%$ & $4.8 \%$ \\
\hline
\end{tabular}

Out of total 25 questionnaires distributed and collected, 22 valid questions were included for analysis with response rate of $92.6 \%$. The descriptive data in the study participant is provided in Table 1-3 and Figure 1-6.
Table 2: Comparison of pre session and post session among $2^{\text {nd }}$ and $4^{\text {th }}$ MBBS students.

\begin{tabular}{|ccccc|}
\hline Students & Parameters & $\begin{array}{c}\text { Pre } \\
\text { session } \\
(\text { mean } \\
\pm \text { SD) }\end{array}$ & $\begin{array}{c}\text { Post } \\
\text { session } \\
(\text { mean } \pm\end{array}$ & $\begin{array}{c}\text { P } \\
\text { value }\end{array}$ \\
\hline \multirow{2}{*}{$\mathbf{2}^{\text {nd }}$ year } & Knowledge & $49.9 \pm$ & $63.03 \pm$ & $<$ \\
& $(19)$ & 4.7 & 5.5 & 0.0002 \\
\cline { 2 - 5 } & Attitude (6) & $49.80 \pm$ & $62.64 \pm$ & $<$ \\
& & 5.5 & 4.3 & 0.0005 \\
\hline $4^{\text {th }}$ year & Knowledge & $47.63 \pm$ & $61.8 \pm$ & $<$ \\
& $(19)$ & 3.8 & 0.9 & 0.001 \\
\cline { 2 - 5 } & Attitude (6) & $48.4 \pm$ & $64.5 \pm$ & $<$ \\
& & 3.6 & 1.2 & 0.0001 \\
\hline
\end{tabular}

Table 3: Comparison in percentage of correct responses.

\begin{tabular}{|lll|}
\hline $\begin{array}{l}\text { Question } \\
\text { number }\end{array}$ & $\begin{array}{l}\text { \% of correct } \\
\text { responses in pre } \\
\text { session }\end{array}$ & $\begin{array}{l}\text { \% of correct } \\
\text { responses in post } \\
\text { session }\end{array}$ \\
\hline 1 & 44.7 & 51.9 \\
\hline 2 & 18.4 & 69.7 \\
\hline 3 & 47.3 & 46.7 \\
\hline 4 & 15.8 & 69.7 \\
\hline 5 & 42.1 & 51.3 \\
\hline 6 & 39.5 & 48.7 \\
\hline 7 & 44.7 & 50.0 \\
\hline 8 & 40.8 & 53.3 \\
\hline 9 & 45.4 & 47.4 \\
\hline 10 & 46.7 & 60.5 \\
\hline 11 & 18.4 & 65.1 \\
\hline 12 & 23.0 & 65.1 \\
\hline 13 & 26.3 & 65.1 \\
\hline 14 & 31.6 & 60.5 \\
\hline 16 & 31.6 & 54.6 \\
\hline 17 & 34.2 & 53.2 \\
\hline 18 & 39.4 & 57.2 \\
\hline 19 & 40.8 & 61.9 \\
\hline 20 & 38.1 & 51.3 \\
\hline 21 & 34.9 & 50.0 \\
\hline 22 & 32.9 & 59.2 \\
\hline 23 & 39.4 & 54.6 \\
\hline 24 & 42.8 & 58.7 \\
\hline 25 & 40.8 & \\
\hline & & 54.6 \\
\hline
\end{tabular}




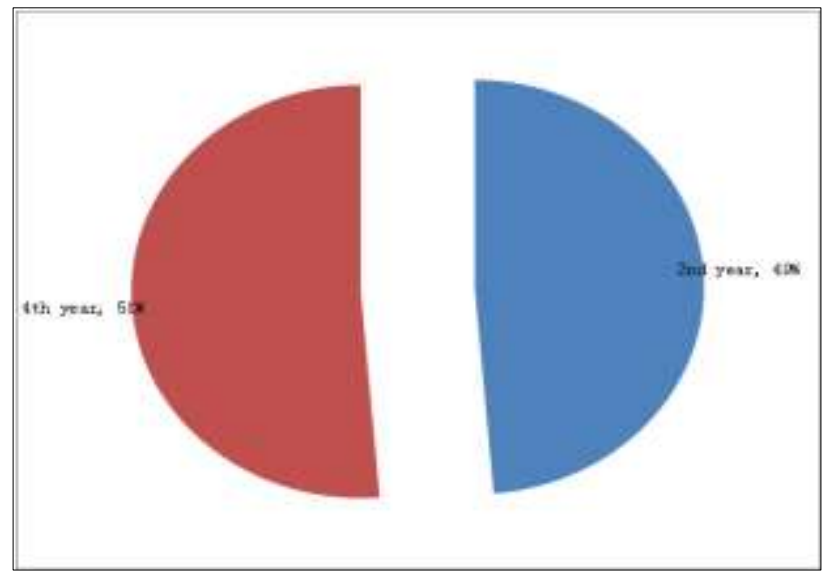

Figure 1: Pie chart showing distribution of students.

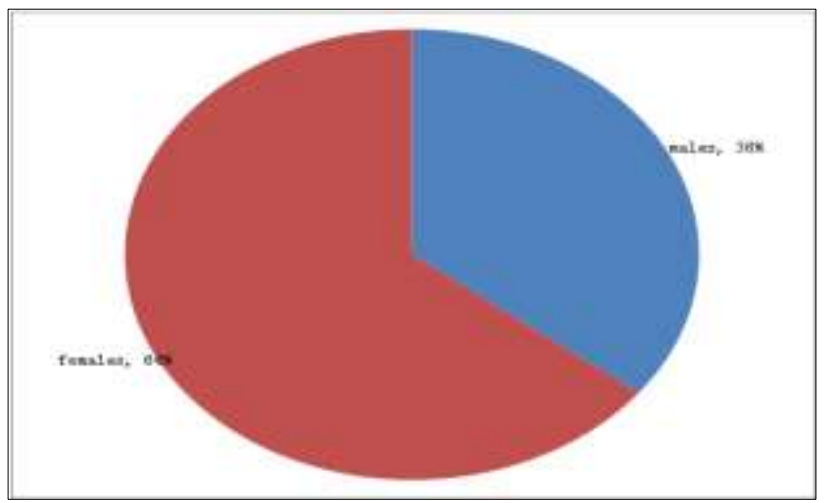

Figure 2: Pie chart showing sex distribution.

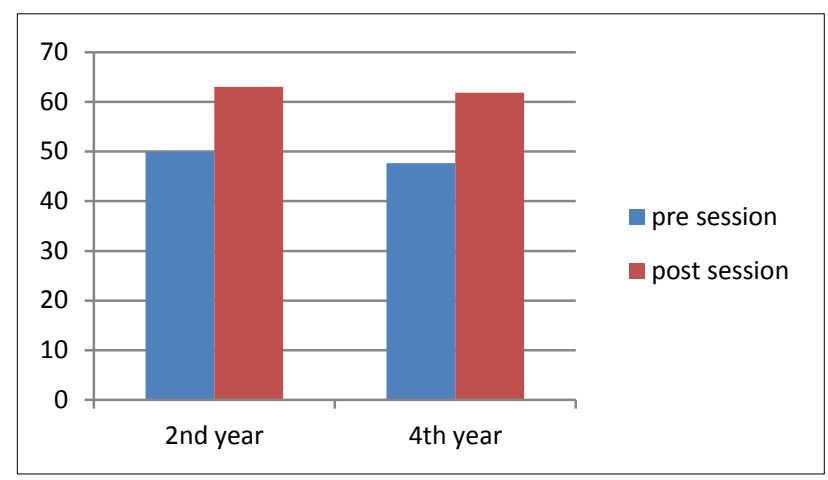

Figure 3: Bar chart showing comparison of pre session and post session mean scores on knowledge.

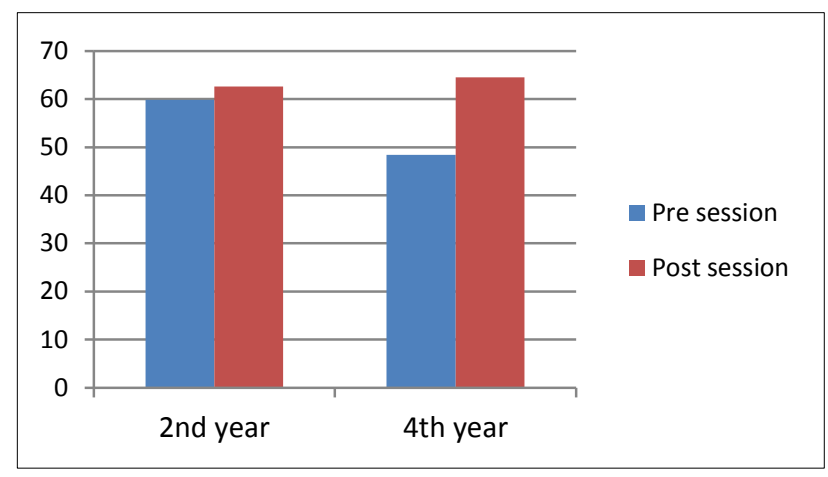

Figure 4: Bar chart showing comparison of pre session and post session mean scores on attitude.

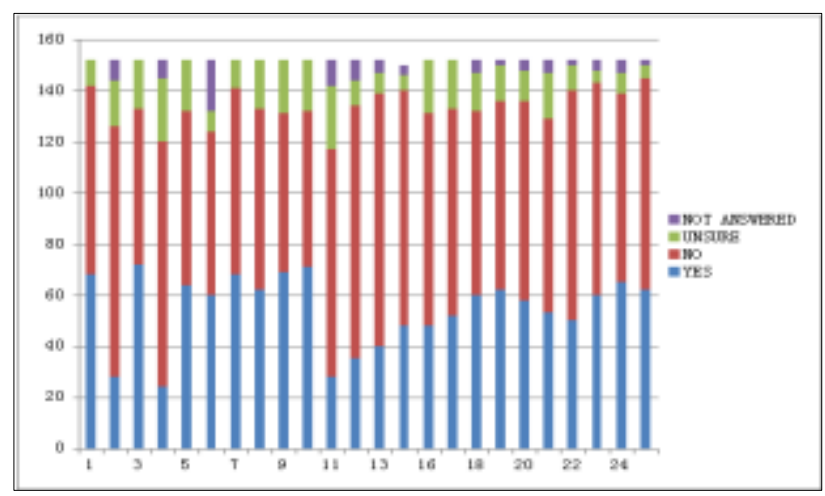

Figure 5: Response of students in pre-session.

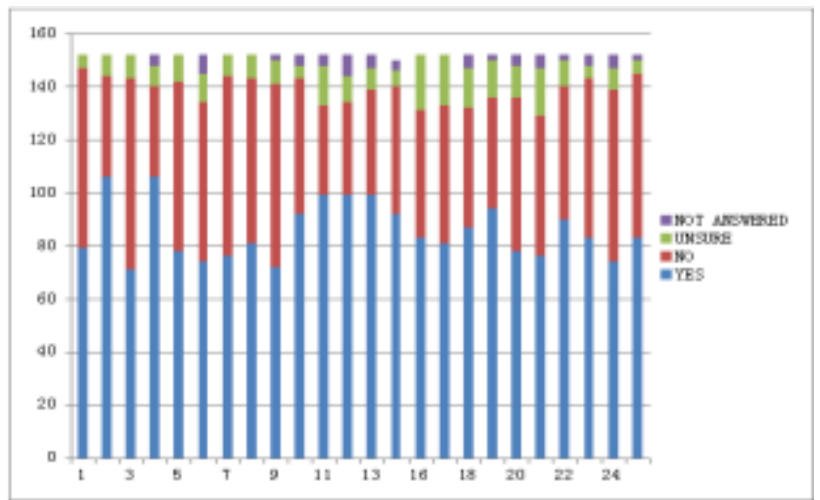

Figure 6: Response of students in post-session.

\section{DISCUSSION}

Modern health care advancements had increased the average life expectancy and the patients with serious illness live longer. But due to the severity of illness the patients cannot lead a comfortable life. They expect medical fraternity to help them by increasing their quality of life.

The undergraduate curriculum for the palliative care is not well structured and has many inadequacies. Palliative care is the active care of dying where the social, emotional, physical, psychological problems of the patients are dealt. The goal of palliative care should continue to focus on the improvement of the quality of life for patients with advanced illnesses. It is based on an interdisciplinary approach that is offered simultaneously with other appropriate medical therapies.

In the pre-educational session, there was an inadequate knowledge about palliative care and pain management with lack of positive attitude indicating the current awareness about palliative care in the medical students. Following the session, there was an overall significant improvement in knowledge, pain management and attitude scores showing the impact of the session and 
ability of the students in gaining knowledge about palliative care, which was similar to previous studies.

Study done by Uwimana et al, had shown that more than half of the primary care physicians lack knowledge regarding the concepts of palliative care. ${ }^{5}$

Meta-analysis done by Billings et al, have shown that there is need for integration of palliative care training at the undergraduate curriculum. The present study supports the view of Billings et al, as palliative care is need of hour for many individuals suffering from severe illness due to increased life expectancy. ${ }^{6}$

Mean scores (42.8 and 82.12) of correct response towards palliative care in $2^{\text {nd }}$ year students pre and post session (Table $3 \&$ figure 5) was less when compared to $4^{\text {th }}$ year students (45.6 and 87.4).

Knowledge and attitude in $4^{\text {th }}$ year medical undergraduates in pre and post session regarding palliative care in comparison to $2^{\text {nd }}$ year medical undergraduates was better as compared by $\mathrm{P}$ value (Table 2) because of clinical practice.

Attitude of the students towards incurable terminal illness did not change much due to educational session as number of people favouring natural death and euthanasia is $90.1 \%$ in the pre session and $95.2 \%$ in the post session (Table 1).

A modest palliative care curriculum can yield improvements in medical student knowledge and attitudes. However, expansion of palliative care skills training and assessment are needed for students to have more meaningful outcomes and to ultimately contribute to better patient outcomes.

\section{CONCLUSION}

Overall level of knowledge about palliative care was poor and dedicated palliative care education is required before MBBS undergraduates enter into clinical care of the patients.

Funding: No funding sources

Conflict of interest: None declared

Ethical approval: The study was approved by the Institutional Ethics Committee

\section{REFERENCES}

1. World Health Organisation. WHO Definition of Palliative Care. Available from: http://www.who.int/cancer/palliative/definition/en/. Accessed on 2013 Dec 08.

2. Khosla D, Patel FD, Sharma SC. Palliative care in India: current progress and future needs. Indian $\mathbf{J}$ Pall Care. 2012;18(3):149-54.

3. Sadhu S, Salins NS, Kamath A. Palliative care awareness among Indian undergraduate health care students: a needs assessment study to determine incorporation of palliative care education in undergraduate medical, nursing and allied health education. Indian J Pall Care. 2010;16(3):154-9.

4. Sullivan AM, Lakoma MD, Block SD. The status of medical education in end of life care. J Gen Int Med. 2003;18(9):685-95.

5. Uwimana J, Struthers P. Met and unmet palliative care needs of people living with HIV/AIDS in Rwanda. Sahara J. 2007;4:575-85.

6. Billings JA, Block S. Palliative care in undergraduate medical education. Status report and future directions. JAMA. 1997;278:733-8.

Cite this article as: Annavarapu S, Marupaka J, Naveen kumar T. Impact of teaching session on concepts of palliative care in medical undergraduates. Int J Basic Clin Pharmacol 2016;5:188-91. 